
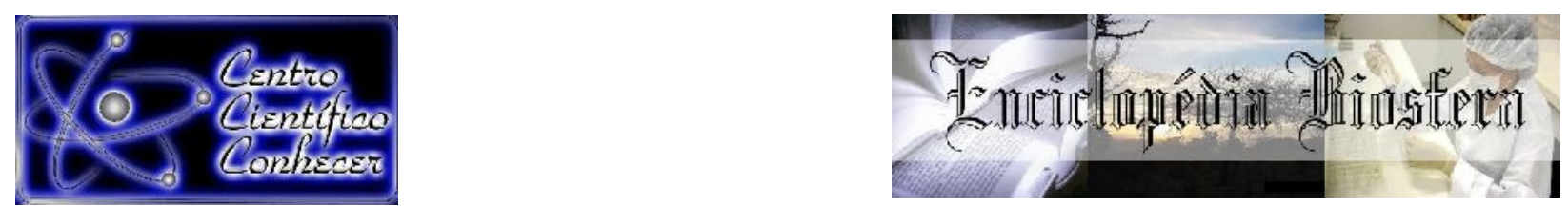

\title{
A IMPORTÂNCIA DO MONITORAMENTO DA UMIDADE DO SOLO ATRAVÉS DE SENSORES PARA OTIMIZAR A IRRIGAÇÃO NAS CULTURAS
}

\author{
Monica Isabelli de Almeida Gutierres ${ }^{1}$; Eletisanda das Neves ${ }^{2}$ \\ ${ }^{1}$ Graduanda do Curso de Agronomia - UNEMAT - Câmpus Universitário de Nova \\ Mutum, Nova Mutum, Mato Grosso, Brasil. \\ ${ }^{2}$ Professora de Educação Superior/Departamento de Agronomia/Eng. Agrícola, \\ UNEMAT - Câmpus Universitário de Nova Mutum, Nova Mutum, Mato Grosso, \\ Brasil. eletisanda@unemat.br
}
Recebido em: 15/02/2021 - Aprovado em: 15/03/2021 - Publicado em: 30/03/2021 DOI: 10.18677/EnciBio_2021A1

\begin{abstract}
RESUMO
O processo de irrigação é uma prática de suma importância para o desenvolvimento agrícola, visando buscar alternativas para suprir às necessidades das culturas por meio de recursos hídricos, métodos e sistema que atendam essa demanda. O conhecimento da umidade do solo indica em que condições hídricas encontra-se a área irrigada, auxiliando na redução dos gastos com água e energia elétrica, necessitando de um planejamento e manejo de irrigação adequado, possibilitando aplicações controladas e pontuadas de água através de métodos específicos de medição da umidade de água no solo, classificados nos métodos diretos e indiretos. Portanto, o objetivo deste artigo foi compreender os aspectos relacionados a irrigação, métodos e equipamentos que possibilitam o planejamento e execução para uma irrigação com eficiência e economia, evitando o desperdício dos recursos hídricos, analisando estudos de pesquisa em diversas referências bibliográficas. Desta forma, foi realizada pesquisa nos sites Google Acadêmico, Blogs, Periódico Scielo, Revista da Engenharia Agrícola, Revista da Engenharia Agrícola e Ambiental, Irriga, Revista Brasileira de Ciências Agrárias, Revista Brasileira de Ciências do Solo, Revista Ibero-Americana de Ciências Ambientais, Site da EMBRAPA e Revista Brasileira de Agricultura Irrigada, dentre outros. Com base nas informações teóricas de diversos autores observa-se a extrema importância de fazer o uso de sensores de umidade quando se pensa na implantação de um sistema de irrigação seja qual for, o sistema e o método utilizado nas culturas selecionadas. O conhecimento da umidade do solo é de grande importância, pois o quanto, o quando e o como irrigar passa a ser prioritário.
\end{abstract}

PALAVRAS-CHAVE: Equipamentos. Irrigação. Umidade do solo.

\section{THE IMPORTANCE OF SOIL HUMIDITY MONITORING THROUGH SENSORS TO OPTIMIZE IRRIGATION IN CROPS}

\section{ABSTRACT}

The irrigation process is a practice of paramount importance for agricultural development, aiming to seek alternatives to meet the needs of crops through water resources, methods and systems that meet this demand. The knowledge of soil moisture indicates the water conditions in the irrigated area, helping to reduce water 
and electricity costs, requiring adequate irrigation planning and management, enabling controlled and punctuated water applications through specific methods. Measurement of water moisture in the soil, classified in direct and indirect methods. Therefore, the objective of this article was to understand the aspects related to irrigation, methods and equipment that enable efficient and economical planning and execution for irrigation, avoiding the waste of water resources, analyzing research studies in several bibliographic references. Thus, research was carried out on the sites Google Scholar, Blogs, Scielo Periodical, Magazine of Engineering Agricultural, Magazine of Engineering Agricultural and Environmental, Irrigation, Magazine Brazilian of Agricultural Sciences, Magazine Brazilian of Soil Sciences, IberoAmerican Magazine of Environmental Sciences, site of EMBRAPA and Brazilian Magazine of Agriculture Irrigation, among others. Based on theoretical information from several authors, the extreme importance of using humidity sensors is observed when considering the implementation of an irrigation system, whatever the system and method used in the selected crops. Knowledge of soil moisture is of great importance, as how much, when and how to irrigate becomes a priority.

KEYWORDS: Irrigation. Soil moisture. Equipament.

\section{INTRODUÇÃO}

A água é uma fonte vital para a manutenção dos ciclos biológicos, geológicos e químicos, mantendo o equilíbrio dos ecossistemas (ECYCLE,2010). Logo, esse recurso natural vem diminuindo, e consequentemente, gerando debates, investigações e direitos sobre a sua utilização, por ser uma preocupação de ordem mundial.

Os recursos hídricos são um dos principais meios que influenciam em diversas atividades econômicas, como por exemplo, a produção agrícola. Segundo Testezlaf (2017), foram encontradas evidências de campos irrigados no Peru (Vale do Zaña) datados de 5.400 anos atrás. Uma técnica assim tão antiga e tão importante deveria ser sempre estudada e avaliada como instrumento essencial para viabilizar o desenvolvimento socioeconômico e cultural de regiões desfavorecidas, onde a produção agrícola é afetada pela escassez de chuvas e pela falta da disponibilidade hídrica, ou para incrementar a lucratividade de regiões agrícolas tradicionais.

No Brasil, a irrigação teve início entre o fim do século XIX e o início do século XX nas lavouras de arroz do Rio Grande do Sul, tendo se firmado como importante polo de irrigação desde então (ANA, 2017). Assim, destaca-se que a irrigação está presente em diversos cultivos, beneficiando a distribuição de água em qualquer época do ano.

Embora sejam reconhecidos todos os benefícios relacionados à irrigação, ainda há dificuldades de se dimensionar sua importância na quantidade produzida atual e o seu papel na segurança alimentar e nutricional da sociedade brasileira devido à indisponibilidade de dados ou à impossibilidade de desagregação em relação a agricultura de uma forma geral (ANA, 2017).

O avanço do conhecimento em relação aos processos de produção é fundamental, particularmente no que se refere às interações entre solo, plantas e água. O solo é um sistema complexo, responsável por assegurar as condições adequadas à produção (HARA et al., 2019). Em especial, a sua capacidade de armazenar água, de forma que está esteja disponível para as plantas (HARA et al., 2019), além de permitir as trocas de gases no ambiente explorado pelas raízes (RABOT et al., 2018). Isto exige um equilíbrio na distribuição do tamanho 
de poros, ou seja, impõe a necessidade da qualidade física do solo, relacionada à preservação da sua estrutura (MOREIRA et al., 2016).

O manejo correto e equilibrado do solo é essencial para que continue a exercer suas funções naturalmente, contribuindo de forma sustentável para o bom funcionamento do ciclo hidrológico (GOMES, 2015). Tem-se que o monitoramento regular da umidade do solo (Us) é fator primordial para o manejo racional da água de irrigação, tanto para estabelecer o momento de irrigar quanto para determinar a lâmina de água a ser aplicada. Ao longo do tempo foram desenvolvidas diversas metodologias e equipamentos para a determinação da umidade do solo, que define o teor de água existente no solo. Entre estes existe grande variação de precisão, de custo e praticidade (BRAGA et al., 2018).

As medidas do teor de água no solo podem ser feitas por meio de: determinação gravimétrica do teor de umidade no solo, utilização de medidores diretos de umidade no solo (sonda de nêutrons, reflectometria no domínio do tempo (TDR)), medidores indiretos de umidade no solo, como os blocos de resistência elétrica, tensiômetros e irrigas (SOUSA et al., 2019).

Assim, foram apresentados equipamentos de baixos e altos custos, destacando segundo Sousa et al., (2019) tais como: os sensores de velocidade de pulso eletromagnético como Reflectometria no Domínio do Tempo (TDR) e os sensores de capacitância por Reflectometria no Domínio da Frequência (FDR), ambos apresentam rapidez nas informações e precisão nos resultados, entretanto ainda não são equipamentos acessíveis economicamente para todo produtor rural.

\section{IRRIGAÇÃO}

Na atividade agrícola, por ser uma grande área de plantação, a utilização da água é realizada através do processo de irrigação, que busca distribuir a água nas plantações em qualquer época do ano. Porém, conforme dados da ANA (2017), em regiões afetadas pela escassez de água em períodos específicos do ano, como na região Sudeste e, principalmente, Centro-Oeste, algumas culturas e safras só se viabilizam com a aplicação suplementar de água nestes períodos, embora a produção possa ser realizada com menores riscos no período chuvoso. Diante desse problema, segundo Idoeta (2015), em algumas regiões, os próprios agricultores apresentaram soluções para manter suas outorgas e evitar que o uso concorra com o consumo humano.

O desenvolvimento crescente da agricultura irrigada no Brasil deve-se a alguns fatores-chave, em especial: a expansão da agricultura para regiões com clima desfavorável (em parte ou durante todo o ano); estímulos governamentais de desenvolvimento regional; e benefícios observados na prática com boa disponibilidade de financiamentos (ANA, 2017).

Vários são os benefícios gerados quando os agricultores passam a utilizar a técnica da irrigação no sistema produtivo, os quais determinam a importância da sua adoção na agricultura (TESTEZLAF, 2017). Assim, tem se tópicos importantes, tais como: garantia de produção com relação às necessidades hídricas e redução dos riscos de quebra de safra devido ao período de estiagem; aumento de produtividade das culturas; melhoria na qualidade do produto final; aumento no número de safras agrícolas e colheita na entressafra; criação e aumento na oferta de emprego; redução de mecanização; e outras oportunidades econômicas (TESTEZLAF, 2017). 
A agricultura irrigada apresenta diversas vantagens, sendo: aumento da produtividade em duas ou três vezes em relação ao cultivo de sequeiro; elevação da renda do produtor; menor oscilação de preço para o consumidor, devido à redução de sazonalidade na produção de alimentos; favorecimento do processo de rotação de culturas e cobertura permanente do solo; e geração de empregos diretos e indiretos. A adoção da irrigação depende de adequada disponibilidade e de boa qualidade da água. Com manejo e gestão, a irrigação pode afetar esses parâmetros e contribuir para que se mantenham em condições favoráveis (SENAR, 2019).

Segundo Barbosa et al. (2015), após as primeiras chuvas é comum, no Semiárido brasileiro, ocorrerem períodos de 20 a 30 dias sem novas chuvas comprometendo seriamente a germinação e o desenvolvimento das culturas, situações em que o ideal seria que os agricultores dispusessem de uma fonte hídrica para aplicar água às culturas nesses intervalos, evitando que as mesmas sofram estresse hídrico, o que inibiria, sem dúvida, o desenvolvimento; esta prática é denominada irrigação de salvação. Nesta região existe, grande quantidade de reservatórios e poços cujas águas podem ser utilizadas na irrigação de salvação; alguns desses reservatórios, por não terem sido construídos para este objetivo específico, necessitam de bombeamento da água até as áreas de plantio.

Para se conseguir o uso eficiente de água, deve-se investir em conhecimentos de manejo da irrigação e capacitação constante do produtor e do trabalhador rural, irrigando com base na demanda hídrica dos cultivos e não apenas no volume de água disponível (SENAR, 2019). Assim a utilização com o cuidado na hora de irrigar já ajuda, segundo Gava et al., (2015) para a utilização de estratégias de irrigação como o déficit hídrico controlado que pode reduzir a utilização de água e energia elétrica. $O$ custo do déficit de irrigação depende do estádio fenológico, do preço do produto e do custo da água e foi maior para os estádios fenológicos relacionados ao período reprodutivo e de formação da produção.

Em áreas que recebem mais de $600 \mathrm{~mm}$ de chuvas anuais, a irrigação pode ser necessária em alguns períodos do ano, de forma a complementar o regime pluviométrico da região, para atender as necessidades hídricas das culturas. Nessas regiões, a distribuição espacial e temporal das chuvas afeta a decisão de se usar a irrigação. Apesar dos altos índices pluviométricos, essas regiões apresentam épocas bem definidas em que a quantidade de chuva não é suficiente para atender as demandas das culturas. Este é o caso da maioria dos Estados do Centro-Oeste e Sudoeste do Brasil (TESTEZLAF, 2017).

Segundo Coelho e Simões (2015), a irrigação eficiente é aquela com menor consumo de energia e menor perda de água, contribuindo para a maior conservação dos recursos hídricos, por ser aplicada no momento correto, isto é, aquele em que a umidade do solo começa a comprometer a absorção de água pela planta. Essa irrigação eficiente requer também a reposição correta da água perdida pelas plantas desde a última irrigação. Os sensores que medem a umidade e a tensão de água do solo são instrumentos para se alcançar uma irrigação eficiente. Contudo, é preciso posicioná-los adequadamente na zona radicular das plantas para que se possa definir corretamente quando irrigar e o quanto deve ser aplicado de água.

As informações das características dos sensores devem ser integradas ao sistema de controle, o qual deve ser trabalhado para que suas respostas 
consigam estabelecer um equilíbrio na umidade do solo de forma que o próprio sistema ajuste o tempo de saída de água necessário para cada planta (MEDEIROS, 2018).

Para se propor um racionamento de água sem prejudicar o meio ambiente é necessário conhecer as características físico-hídricas do solo, o clima, a cultura e o funcionamento dos equipamentos de irrigação, evitando desperdícios da água na irrigação das plantações (IDOETA, 2015).

\section{MÉTODOS E SISTEMAS DE IRRIGAÇÃO}

Os parâmetros do manejo e a gestão da irrigação na aplicação da água onde tenha boa disponibilidade e o uso de uma tecnologia adequada para melhoria na agricultura. Tem sido visto em alguns cursos ofertados pelo SENAR nas informações apresentadas por esta instituição existem diferentes características operacionais e custos de implantação, que podem variar em função da região e tecnologia agregada quando se pensa em implantar um sistema de irrigação (SENAR, 2019).

A escolha da área de irrigação deve seguir alguns critérios e procedimentos para o sucesso do sistema empregado, sendo esses os principais: o solo utilizado para irrigação não deve ser compactado, pois se for o caso a compactação dificulta a passagem da água no solo e causa perda de água, dentre outros problemas; é necessário que a área escolhida tenha uma fonte hídrica para fornecimento da água de irrigação durante todo o ciclo de cultivo; uma análise da água disponível para conhecer sua qualidade, tendo em vista que águas de qualidade inferior podem causar problemas como salinização do solo e/ou obstrução dos emissores utilizados, diminuindo a eficiência do sistema; o técnico deve fazer o pedido de outorga para legalização do uso da água; é importante que a área não esteja muito distante da fonte de água, evitando com isso o investimento muito elevado em tubulações e conexões; também atentar quando a fonte de água for um rio devendo-se adotar a distância entre a suas margens (NASCIMENTO, 2017).

O método de irrigação é a forma da aplicação da água nas culturas, dividido em quatro métodos: superfície, aspersão, localizada e subsuperfície, estando ligados aos sistemas de irrigação (SENAR, 2019). No primeiro método a água é disposta na superfície do solo e o nível é controlado para aproveitamento das plantas. No método subterrâneo (ou subsuperficial), a água é aplicada abaixo da superfície do solo, formando ou controlando o lençol freático, na região em que pode ser aproveitada pelas raízes das plantas. Na irrigação por aspersão, a água é aplicada sob pressão acima do solo, por meio de aspersores ou orifícios, na forma de uma chuva artificial. O método localizado (ou microirrigação) consiste na aplicação em uma área bastante limitada, utilizando pequenos volumes de água, sob pressão, com alta frequência. Existem diferentes sistemas para cada um desses métodos, como por exemplo, o sistema por inundação na irrigação superficial; o sistema de pivô central na irrigação por aspersão; e o sistema de gotejamento que ocorre nos métodos subterrâneo e localizado, conforme ANA (2017).

Segundo Testezlaf (2017), a irrigação por inundação, como o próprio nome informa, é a aplicação de água em uma cultura de forma a alagar a área de cultivo, exigindo a adequação em bacias ou tabuleiros, principalmente na cultura do arroz, em regiões onde preponderam pequenas propriedades; e a irrigação por sulcos é o sistema de irrigação por superfície que aplica a água para as plantas 
através de pequenos canais ou sulcos paralelos às linhas de plantio, por onde se movimenta ao longo do declive.

As condições de cultivo e as necessidades da agricultura exigiram, com o passar do tempo, o desenvolvimento de diferentes sistemas de irrigação por aspersão, como por exemplo: sistemas portáteis e semiportáteis para transporte manual ou mecanizado, sistemas fixos estacionários ou permanentes, com aplicação por cima ou por baixo da folhagem, operando com diferentes níveis de pressão e vazão. Assim, existe no mercado uma variedade de sistemas de irrigação por aspersão que podem ser adaptados às mais diversas situações de operação e funcionamento (TESTEZLAF, 2017).

Um sistema de irrigação por aspersão é composto geralmente pelas seguintes partes: bombeamento, tubulação e acessórios (transporte) e aspersores ou sprays (distribuição). Tradicionalmente no Brasil, os sistemas de aspersão são projetados sem as unidades de tratamento da água, apesar da baixa qualidade da água superficial utilizada, e também das unidades de automação e controle. Esse procedimento pode levar a sérios comprometimentos da durabilidade dos equipamentos e a uma eficiência de aplicação não apropriada a esse tipo de irrigação (TESTEZLAF, 2017).

Ainda segundo o autor acima a irrigação localizada se caracteriza pela aplicação de pequenos volumes de água com alta frequência; é possível visualizar que esse sistema de irrigação é composto pela estação de bombeamento, cabeçal de controle, sistema de distribuição de água composto por linhas principais, de derivação e laterais, emissores, válvulas e outros dispositivos. Obtendo duas opções, sendo: irrigação por gotejamento que compreende os sistemas onde a aplicação da água e de produtos químicos é realizada na forma de gotas por uma fonte pontual, denominado gotejador. Esses emissores operam com pressões que variam entre 50 a $200 \mathrm{kPa}$ e vazões na ordem de 0,5 a $12 \mathrm{Lh}^{-1}$.

A irrigação por microaspersão se caracteriza pela aplicação da água e de produtos químicos, numa fração do volume de solo explorado pelas raízes das plantas, de forma circular ou em faixa contínua, realizada por microaspersores, que são aspersores de pequenas dimensões. Nesse sistema, as pressões variam geralmente de 100 a $300 \mathrm{kPa}$, e as vazões de 30 a $200 \mathrm{Lh}^{-1}$. Os sistemas de irrigação localizada, quando corretamente projetados e bem manejados, apresentam vantagens sobre os outros sistemas de irrigação, como também permite melhor aproveitamento dos recursos hídricos, pois irriga apenas a área ao redor da planta, diminuindo assim, a evaporação direta da água do solo para a atmosfera e as perdas por escoamento superficial (TESTEZLAF, 2017).

De acordo com Testezlaf (2017), o método de subirrigação e seus sistemas consiste na prática de irrigação diretamente na raiz, onde o lençol freático é mantido a uma certa profundidade de forma natural ou artificial, permitindo o fluxo de água adequado à cultura. Para esse método são utilizados os sistemas por gotejamento subterrâneo ou subsuperficial, elevação do lençol freático e sistema de irrigação em ambiente protegido.

O gotejamento subterrâneo são linhas de gotejamento enterradas no solo a profundidade que permita que a água aplicada atinja o volume explorado pelas raízes. Já na elevação do lençol freático é empregado em áreas onde existe a ocorrência de camadas de impedimento subsuperficiais, que permite saturar 0 perfil do solo e controlar a profundidade do nível do lençol freático, deixando-o próximo às raízes das plantas. Por último, os sistemas de subirrigação em 
ambientes protegidos, utilizam do princípio de aplicação de água diretamente nas raízes das culturas (TESTEZLAF, 2017).

As técnicas de irrigação, segundo ANA (2017), não apresentam um método ou sistema de irrigação ideal a priori. A irrigação superficial é mais econômica e apresenta menos tecnologia atrelada. Mas um terreno com boa infiltração e maior declividade não é favorável a esse método, mas pode ser para a aspersão que, por sua vez, não será adequada para regiões com ventos fortes. Os métodos localizados, em que pesem as altas eficiências, não são adequados para culturas temporárias (milho, feijão, arroz, soja), requerem boa qualidade da água e possuem alto custo de implantação e manutenção. Esses exemplos realçam que a seleção do método e do sistema para determinado local passam por uma avaliação integrada de componentes socioeconômicos e ambientais, incluindo a disponibilidade e a qualidade da água. Após a seleção de método e do sistema, a eficiência qualiquantitativa do uso da água passa a ser função do manejo adequado das culturas, dos equipamentos e dos recursos ambientais.

A seleção do método e do sistema para uma determinada área irrigada, depende da avaliação dos componentes socioeconômicos, ambientais, disponibilidade e a qualidade da água, equipamentos e manejo adequado das culturas (ANA, 2017). Contudo, no sistema integrado, segundo Balbino (2016), a coleta de variáveis de diferentes fontes, possui maior precisão na geração de informações, tornando-se um fator primordial no sucesso dos empreendimentos agrícolas.

\section{MANEJO DE IRRIGAÇÃO}

Atualmente para que o produtor rural tenha um retorno financeiro viável e garanta uma alta produtividade é necessário que desenvolva o processo de irrigação, conhecendo técnicas que permitem o uso eficiente da água, evitando desperdícios e gastos com energia elétrica (ANA, 2017).

O manejo da irrigação consiste na determinação do momento, da quantidade e de como aplicar a água na plantação, levando em consideração outros aspectos do sistema produtivo como o controle fitossanitário, as condições meteorológicas, econômicas e as estratégias de condução da cultura de acordo com Balbino (2016). Nesta linha de pensamento o SENAR (2019), coloca que essa técnica deve ser analisada priorizando duas etapas: engenharia da irrigação (como irrigar) e ciência da irrigação (quando e quanto irrigar), analisando os sistemas de irrigação, o solo, clima, água e a planta para alcance de sucesso efetivo perante os procedimentos.

O manejo ou gerenciamento da irrigação tem, então, os seguintes objetivos: promover o uso eficiente da água; reduzir o custo de água e energia; aumentar a produtividade da cultura; melhorar a qualidade do produto; aumentar a eficiência dos fertilizantes e diminuir a incidência de pragas e doenças (SENAR, 2019).

O manejo da irrigação pode ser via solo, de acordo com Dabach et al. (2016), tem como princípio determinar a umidade do solo do sistema radicular, repondo o volume de água necessário no solo. Assim as plantas são regadas com mais frequência, mas tudo depende da curva de retenção, que indicará o volume adequado para cada tipo de solo.

Para pequenos produtores essas informações são praticamente inexistentes, levando em consideração que para fazer o manejo de irrigação são necessários instrumentos caros que para serem usados necessitam de um 
treinamento específico. Porém pode-se fazer um manejo de irrigação gastando pouco e minimamente eficiente (NASCIMENTO, 2017).

Existem três processos de manejo de irrigação: processos baseados nas condições atmosféricas, nas condições de umidade do solo e nas condições de água na planta. Pode ser feito também o manejo integrado, que recomenda a irrigação baseada nas condições da atmosfera e do solo, conjuntamente (BALBINO, 2016).

Em condições via solo e atmosfera para o manejo da irrigação integrada é indicada para todos os sistemas de irrigação e tipo de cultura. Pela atmosfera tem maior precisão na detecção do momento das irrigações e auxilia na adequação da lâmina de irrigação, pois toda a irrigação é feita com base na evapotranspiração e é monitorada pelos sensores de umidade instalados no solo. Já por via solo, condiciona o solo a manter-se com teor de água adequado favorecendo o desenvolvimento da cultura, além de não interferir nos tratos fitossanitários (BALBINO, 2016).

Nesse sistema de manejo, quando é utilizado a via atmosfera são coletados dados tanto do solo como do clima, que são relacionados com o estágio fenológico da cultura, de forma a gerar a recomendação mais precisa, como a exata quantidade de água necessária em todos os momentos do crescimento e desenvolvimento da cultura. Por ser uma técnica bastante difundida, principalmente para grãos, que permite o monitoramento eficaz das condições meteorológicas na região e suas influências no consumo de água da planta através da evapotranspiração. Pode ser aplicado para várias culturas, em diferentes fases de desenvolvimento em um mesmo local porque o balanço hídrico considera todos os fluxos de água que entram e saem do volume de solo explorado pelas raízes. As componentes de entrada do balanço são a precipitação, a irrigação e o orvalho. O orvalho possui uma ordem de magnitude menor que o consumo diário de uma vegetação em locais úmidos, em regiões ou épocas secas sua contribuição é desprezível em termos de suprimento de água para o cultivo. No entanto, a precipitação e irrigação são os principais componentes de entrada do balanço hídrico (BALBINO, 2016).

A determinação das necessidades hídricas da cultura é estimada com base nos valores de evapotranspiração associados com o coeficiente do cultivo (Kc), possibilitando determinar a quantidade de água a ser suprida ao solo. $O$ balanço hídrico para controle de irrigação considera as variáveis atmosféricas exigidas (radiação, vento, umidade e temperatura) para estimar a evapotranspiração, além da precipitação. Estes dados são coletados com a instalação de uma estação meteorológica na propriedade (BALBINO,2016).

O outro manejo via solo, com a implantação de equipamentos direto no solo, pode medir a disponibilidade hídrica para as plantas. A capacidade de retenção hídrica de um solo é conhecida como Capacidade de Água Disponível (CAD), que considera um limite máximo onde a água não está sendo perdida por percolação e um limite mínimo onde a água está tão aderida aos poros dos agregados do solo que é indisponível para as plantas. O ponto máximo é chamado de Capacidade de Campo (CC) e o ponto mínimo de Ponto de Murcha Permanente (PMP). Antes de implementar esse tipo de manejo é necessário conhecer as características físico-hídricas do solo (BALBINO, 2016).

O solo possui características que indicam a sua capacidade em reter a água no solo. Isso é importante para o balanço hídrico de irrigação, pois com essa capacidade tem-se o máximo de água que pode irrigar e o momento certo. Essas 
características são obtidas com a curva característica de água no solo, que é determinada por uma amostra de solo enviada a algum laboratório de física do solo (BALBINO, 2016).

\section{FATORES QUE INFLUENCIAM A UMIDADE E ARMAZENAMENTO DE ÁGUA DO SOLO NO MANEJO DE IRRIGAÇÃO}

O conhecimento do manejo de água no solo tem ganhado cada vez mais importância visto os problemas hídricos atuais. A agricultura irrigada utiliza grandes volumes de água e depende do conhecimento aprofundado nesse assunto para ter maior eficiência de aplicação de água. Os métodos mais utilizados para o correto manejo de irrigação são aplicados através dos dados atmosféricos ou do acompanhamento da umidade do solo (GAVA et al., 2016).

$\mathrm{Na}$ tensiometria, os tensiômetros, após instalados em campo, permitem realizar medidas momentâneas, porém, para correlacionar a leitura do equipamento com o verdadeiro valor da umidade do solo, é preciso conhecer a curva de retenção de água daquele solo, obtida através de metodologia laboratorial. Apesar de ser um processo trabalhoso, após confeccionada a curva, esta poderá ser usada sempre para o mesmo solo (GAVA et al.,2016).

Segundo Kitić e Bengin (2013), a umidade do solo é um elemento de água presente no espaço poroso do solo. O conhecimento da umidade do solo é essencial para a cultura irrigada, por indicar em que condições hídricas o solo encontra-se, auxiliando na redução dos gastos com água e energia elétrica. $\mathrm{O}$ monitoramento determinará quando e quanto irrigar, com aplicações controladas e pontuais de água.

A irrigação, se realizada com um manejo adequado, permite economizar água e energia, manter teores de umidade no solo favoráveis ao ótimo desenvolvimento das plantas, a obtenção de altas produtividades e produtos de boa qualidade. No manejo adequado da irrigação, o agricultor precisa utilizar técnicas e procedimentos para definir: quanto irrigar, quando irrigar e como irrigar (SOUSA et al., 2019).

A questão "quanto irrigar" refere-se à quantidade de água a ser aplicada, que é determinada pela necessidade hídrica da cultura, podendo ser estimada por meio da evapotranspiração. Para se definir "quando irrigar" ou o momento da irrigação pode-se adotar o estabelecimento de turno de rega fixo ou turno de rega variável. No caso da utilização do turno de rega variável, o momento da irrigação pode ser determinado utilizando medidas de avaliação do estado da água no solo, balanço de água no sistema radicular e medidas de água na planta. O "como irrigar" é a forma como a água é conduzida até a planta, que é definida pelo método e sistema de irrigação (SOUSA et al., 2019).

A importância da umidade no solo em sistemas agrícolas e o monitoramento são fundamentais, principalmente em regiões em que a disponibilidade de água se torna restritiva, como por exemplo, no semiárido brasileiro. Porém, é preciso monitorar e manejar adequadamente para ter efeitos positivos na irrigação (SOUSA et al., 2019).

Esse monitoramento de umidade pode ser feito diretamente, a partir da coleta de amostras e a determinação da umidade pelo método padrão de estufa, mas é mais comum que seja feito de forma indireta, por meio de sensores de umidade, que podem ser artesanais ou comerciais (SENAR, 2019). 


\section{EQUIPAMENTOS PARA MEDIR A UMIDADE DO SOLO}

A irrigação eficiente é aquela com menor consumo de energia e menor perda de água, contribuindo com a maior conservação dos recursos hídricos, por ser aplicada no momento correto, isto é, aquele em que a umidade do solo começa a comprometer a absorção de água pela planta. Essa irrigação eficiente requer também a reposição correta da água perdida pelas plantas desde a última irrigação. Os sensores que medem a umidade e a tensão de água do solo são instrumentos para alcançar uma irrigação eficiente (COELHO; SIMÕES, 2015).

No monitoramento da umidade do solo, existem métodos importantes classificados em métodos diretos, indiretos e remotos. Nos métodos diretos se faz a extração de água de uma amostra de solo por meio de evaporação, lavagem e reação química, nos indiretos se faz a medição das características do solo, dependendo do conteúdo de água. Nesse indireto pode-se analisar também as características de um determinado objeto do solo, semelhante a um material absorvedor poroso. Nas medições remotas, a umidade do solo é analisada através de dados de satélite que utilizem o reflexo da radiação eletromagnética de um espectro específico da superfície do solo (EOS, 2020).

O uso de sensores eletromagnéticos, como método indireto pode apresentar-se como uma das alternativas viáveis, quando se tem problemas para o monitoramento do solo, até porque estes podem fornecer e registrar dados atualizados de conteúdo de água armazenada de maneira não destrutiva e instantânea (GOMES et al., 2017; PIZETTA, 2017), levando a redução significativa do uso da água em que pode manter ou mesmo elevar os rendimentos da cultura implantada (GASCH et al., 2017; PEREIRA et al., 2018).

Os sensores que medem a umidade e a tensão de água do solo são instrumentos para se alcançar uma irrigação eficiente. Assim, segundo o SENAR (2019), tem-se o Irrigás um sensor simples e de baixo custo, desenvolvido pela Embrapa, que pode ser adquirido no mercado ou construído artesanalmente pelo produtor. O Irrigas comercial é vendido em três versões com cápsulas de 15, 25 e $40 \mathrm{kPa}$. O filtro de $15 \mathrm{kPa}$ indica a hora de irrigar mais cedo do que o outro de 40 $\mathrm{kPa}$ e o tensiômetro é um sensor prático e preciso. É constituído por uma cápsula porosa, conectada a um tubo de PVC que contém o instrumento de leitura (chamado tensímetro), sendo seu interior preenchido com água. Também são comercializados tensiômetros sem o equipamento de leitura, chamados tensiômetros de punção. Nesse caso, o produtor deve adquirir o equipamento de leitura (tensíometro ou vacuômetro) separadamente.

$\mathrm{O} \mathrm{kPa}$ é apenas uma unidade de medida de pressão. Assim, o Irrigas de $40 \mathrm{kPa}$ é o que tem poros menores, mais finos. Este segura a água com mais força e por mais tempo. O de $15 \mathrm{kPa}$ é o de poros maiores. Este segura a água com menor força. Quando instalados no campo, o Irrigas de $15 \mathrm{kPa}$ vai indicar a hora de irrigar mais cedo do que o outro de $40 \mathrm{kPa}$ (MAROUELLI et al.,2010).

Os estudos de medições, segundo Silva et al. (2018) utilizam vários experimentos numéricos e estes autores investigaram o efeito do posicionamento dos sensores de umidade do solo na eficiência da irrigação, revelando que a eficiência da irrigação variou consideravelmente entre as diferentes posições dos sensores investigados. Assim, o conhecimento da variabilidade na extração de água pode diminuir a confiabilidade do balanço hídrico do solo; portanto, é necessário definir a colocação de sensores de água no solo na zona da raiz para medições confiáveis da umidade do solo, mesmo sob variações de extração de água da raiz. Em um estudo recente, conforme Silva et al.(2018), foi introduzido o 
conceito de posições representativas estáveis no tempo (TSRPs) e indicou uma considerável variabilidade na representatividade das leituras dos sensores de acordo com sua colocação, bem como sua configuração de sistema de representatividade e condições meteorológicas.

Quando se trabalha com sensores de umidade, algumas dúvidas podem surgir, tais como; quantidade de sensores, profundidade adequada, espaçamento entre eles, e qual é o limite critico de água no solo. Em pesquisas realizadas por Soulis et al. (2016) ; Silva et al. (2018) e Soulis e Elmaloglou, (2018) esses autores adotaram como tomada de decisão, o conhecimento da estabilidade temporal e espacial do conteúdo de água existente no solo. O local que apresenta uma estabilidade temporal do conteúdo de água no solo em relação à umidade média quando se analisa o perfil do solo, foi definida por Soulis e Elmaloglou (2016) como posições que representam bem a estabilidade temporal.

Para reduzir a quantidade de sensores necessários num local específico com o objetivo de monitoramento da umidade em um determinado volume do solo, é imprescindível o conhecimento do local que apresenta estabilidade temporal do conteúdo de água no solo, pois o local torna-se representativo na umidade média da área completa de investigação (LI; SHAO, 2014).

Para rápida determinação do teor de umidade e monitoramento, métodos indiretos podem ser utilizados e calibrados por meio do método padrão. $O$ método padrão para determinação do teor de umidade de uma amostra de solo é realizado em laboratório, fazendo-se a pesagem do solo úmido e posterior secagem do material em estufa em temperatura de $105 \pm 3^{\circ} \mathrm{C}$ durante $24 \mathrm{~h}$, e nova pesagem do material (OLIVEIRA, 2018).

Os principais métodos indiretos baseiam-se em medidas como a sonda de nêutrons, a resistência do solo à passagem de corrente elétrica e a constante dielétrica do solo ou a Reflectometria no Domínio do Tempo (TDR). Estas são características do solo que variam com a sua umidade (OLIVEIRA, 2018).

A sonda de nêutrons consiste essencialmente de duas partes: a placa com a sonda que é inserida no solo e o sistema de contagem eletrônica. Este equipamento contém uma fonte radioativa que emite nêutrons rápidos, um detector de nêutrons lentos e um pré-amplificador. O sinal do pré-amplificador passa por 5 a $20 \mathrm{~m}$ de comprimento no cabo para o sistema de contagem eletrônica. Já o sensor resistivo de umidade do solo funciona monitorando a variação da resistência elétrica entre dois eletrodos embutidos no solo. A resistência elétrica medida pelo sensor é inversamente proporcional à umidade do solo (OLIVEIRA, 2018).

Embora, os sensores do tipo TDR medem a velocidade da propagação das ondas eletromagnéticas nas hastes que ficam em contato íntimo com o solo. O pulso de voltagem emitido ao longo da haste metálica de comprimento irá propagar-se até o final desta, onde encontrará um estrangulamento eletrônico, causado pela mudança de impedância, ou seja, a descontinuidade da haste metálica, provocando o retorno de um pulso ressonante até o início (OLIVEIRA, 2018). No entanto, dependendo da precisão requerida e em razão da variabilidade das características físicas que os solos possuem, os sensores utilizados para estimar de forma indireta o teor de água no solo requerem calibrações locais, seja em campo ou em laboratório para aumentar a precisão nas medições sendo necessária a calibração do equipamento para cada tipo de solo (OLIVEIRA, 2018). 
A realização da calibração dos sensores é indispensável para os solos a serem monitorados, em virtude das diferenças físicas e químicas que os mesmos apresentam. De acordo com Gava et al. (2016), os autores encontraram um desvio de leitura do sensor de umidade para a medida real, em diferentes tipos de solos, no qual foi de $-8 \%$ para o solo de textura argilosa e de $-4 \%$ para o solo de textura arenosa. Em cada tipo de solo, os sensores se comportam de forma diferenciada e devido a esse fato podem registrar dados acima ou abaixo das medições reais. É evidente que a precisão das leituras destes sensores dependem também da qualidade do instrumento, da calibração, a qual pode variar com o tipo de solo estudado (GAVA et al., 2016).

Os sensores eletrônicos podem ser muito precisos, porém, o seu erro está ligado à qualidade do equipamento e/ ou a condição de calibração inicial. Uma vez calibrado $24 \mathrm{~h}$ na condição de campo e de forma correta, um sensor de umidade passa a fazer leituras reais dos teores de água no solo (SILVA et al., 2012; OLIVEIRA, 2018). Neste contexto, Gomes et al. (2017), que trabalharam com a calibração de um sensor de umidade do solo de baixo custo concluíram que o sensor por ter uma área de contato pequena, precisa de um maior número de avaliações e/ou de sensores ao longo do perfil do solo para melhor representatividade da umidade do solo.

Com o intuito de estimar a umidade do solo implantado com a cultura da cana-de-açúcar irrigada e avaliar a extração de água utilizada pelas plantas durante o período de maturação Oliveira et al. (2016), avaliaram a utilização da técnica de sensores eletrônicos e concluíram que este método teve eficiência para monitorar a dinâmica e a estimativa de água no solo.

Se o poder econômico do produtor é satisfatório e, este esteja com disponibilidade para investir, o recomendado é que ele instale sensores em um plano bidimensional do bulbo úmido ou até mesmo da parte radicular. Com isso, ele define o melhor posicionamento do sensor de umidade do solo, para a realização dos cálculos de lâmina de irrigação naquele determinado dia (FREITAS, 2017).

\section{CONSIDERAÇÕES FINAIS}

A água é um elemento vital para as plantas, desta forma a prática de irrigação é a técnica essencial para o desenvolvimento da agricultura, fornecendo água às plantas na dose e frequência recomendadas. Assim a escolha de como vai ser aplicada, dependerá da metodologia selecionada pelo produtor no manejo de irrigação. A utilização de forma inapropriada da água nas culturas pode prejudicar o cultivo, pode contaminar o solo e lençóis freáticos, levando a grandes prejuízos financeiros e quedas na produtividade.

Considerando os fatores citados acima, o uso da irrigação associada à tecnologia facilitará ao produtor todos os dados necessários para aplicação da água, aumentando a eficiência da produção agrícola, diminuindo o desperdício de água e de energia elétrica, e reduzindo o impacto ambiental, além de reduzir mão de obra.

Desta forma pode-se fazer um comparativo em relação aos equipamentos que determinam a umidade do solo, destacando o Irrigas e Tensiômetro, considerados os mais baratos e de fácil acesso aos produtores da agricultura familiar até os grandes produtores, atendendo qualquer tipo de cultura. Mas durante a o processo de revisão ficou claro que o TDR e o FDR são instrumentos que mais demonstraram resultados de eficiência nos requisitos rapidez de 
processamento e dados, com resultados de precisão, porém os seus altos custos impossibilitam de ser aproveitado em toda cultura irrigada. Mas aos poucos o produtor vai se adequando e planejando os seus recursos financeiros, através de bons projetos de irrigação e incentivos governamentais que possibilitarão a automação da cultura Irrigada de precisão em toda cultura e território brasileiro.

Os sensores eletrônicos estão sendo utilizados na agricultura como ferramenta de monitoramento do conteúdo de água no solo. O uso em grande escala visa auxiliar o produtor na tomada de decisão de quando e quanto irrigar, desta maneira tendo como consequência a maximização e qualidade da produtividade.

Observa-se a extrema importância de se fazer o uso de sensores de umidade quando se pensa na implantação de um sistema de irrigação seja qual for o sistema e o método utilizado nas culturas selecionadas, as vantagens são diversas, uma vez que quando se utiliza irrigação o produtor quer alta produtividade e qualidade do produto. O conhecimento da umidade do solo é de grande importância, e nesse contexto, trabalhar o manejo de irrigação é um fator que se sobressai, pois o quanto, o quando e o como irrigar passa a ser mais adequado para as culturas.

\section{REFERÊNCIAS}

ANA - Agência Nacional de Águas. Atlas irrigação: uso da água na agricultura irrigada. Brasília, 2017.

BALBINO, A. 3 formas de fazer o manejo da irrigação na lavoura. AgroSmart Blog, 2016. Disponível em: <https://agrosmart.com.br/blog/3-formas-de-fazer-omanejo-da-irrigacao-na-lavoura/.> Acesso em: 21 jul. 2020.

BARBOSA, A.G.; SILVA, M.S.L.; ANJOS, J.B; OLIVEIRA NETO, M.B.; Tecnologias de captação, manejo e uso da água de chuva no setor rural. Captação, Manejo e uso de água de chuva. Cap. 11. Campina Grande - PB, 2015.

BRAGA, M.B.; GUEDES, I.M.R.; SILVA, J.; LIMA, C.E.P. Determinação Simplificada da Umidade do Solo Visando o Manejo de Irrigação em Hortaliças. Boletim de Pesquisa e Desenvolvimento 155. Empresa Brasileira de Pesquisa Agropecuária-Embrapa Hortaliças, ISSN 1677-2229 Julho, 20p. 2018 Disponível em: https://ainfo.cnptia.embrapa.br/digital/bitstream/item/180567/1/BPD-155.pdf Acesso em: 10 fev. 2021.

COELHO, E.F.; SIMÕES, W.L. Onde posicionar sensores de umidade e de tensão da água do solo próximo da planta para um manejo mais eficiente da água de irrigação. Circular Técnica 109. Cruz das Almas: BA. Embrapa. ISSN 1809-5011. 2015.

DABACH, S. SHANIA, U; LAZAROVITCH, N. The influence of water uptake on matric head variability in a drip-irrigated root zone. Soil \& Tillage Research, Amesterdã, v.155, p. 216-224, 2016. DOI: 10.1016 / j.still.2015.08.012 Disponível em: <https://www.cabdirect.org/cabdirect/abstract/20163002005.> Acesso em: 12 set. 2020. 
ECYCLE, Equipe. Qual a importância da água? Publicações em 2010 - 2021. Disponível em: <https://www.ecycle.com.br/8446-importancia-da-agua.html.> Acesso em: 21 jul. 2020.

EOS - EARTH OBSERVING SYSTEM. Disponível em: https://eos.com/pt/blog/umidade-do-solo/. Acesso em: 13 nov. 2020.

FREITAS, F. T.O. Critérios para o manejo da irrigação via solo no cultivo de maracujazeiro Dissertação de Mestrado em Engenharia Agrícola (Agricultura Irrigada e Recursos Hídricos) Universidade Federal do Recôncavo da Bahia, $2017 . \quad 72 p$ Disponível em: https://www.ufrb.edu.br/pgea/images/Teses/FABIO_TAYRONE_OLIVEIRA_DE_F REITAS.pdf. Acesso em: 13 nov.2020.

GASCH, C.K.; BROWN, D.J.; BROOKS, E.S.; YOUREK, M.; POGGIO, M. et al. A pragmatic, automated approach for retroactive calibration of soil moisture sensors using a two-step, soil-specific correction. Computers and Electronics in Agriculture, v.137, p. 29-40, 2017.

GAVA, R.; FRIZZONE, J. A.; SNYDER, R.L.;VIEIRA,J.J.; JUNIOR, E. F.F et al. Estresse hídrico em diferentes fases da cultura da soja. Revista Brasileira de Agricultura Irrigada, vol. 9, p. 349-359, 2015. Disponível em: DOI: 10.7127/rbai.v9n600368.

GAVA, R.; SILVA, E.E.; BAIO, F.H.R. Calibração de sensor eletrônico de umidade em diferentes texturas de solo / electronic moisture sensor calibration in different soil textures. Revista Brasileira de Engenharia de Biossistemas, v. 10, n. 2, p. 154-162, 2016.2 Disponível em: DOl: http://dx.doi.org/10.18011/bioeng2016v10n2p154-162. Acesso em:28 out 2020.

GOMES, M.A.F. Importância do solo para a água subterrânea. Uso Agrícola das Áreas de Afloramento do Aquífero Guarani no Brasil - implicações para a água subterrânea e propostas de gestão com enfoque agroambiental. Opinião do livro, p. 30, 2015.

GOMES, F.H.F.; CUNHA, F.N.; LOPES FILHO, L.C..; VIDAL, V.M.;SOARES,F.A.L. et al. Calibração de um sensor de umidade do solo de baixo custo. Revista Brasileira de Agricultura Irrigada v.11, ํo.4, p. 1509 - 1516, 2017 ISSN 1982-7679 (On-line) Fortaleza, CE, INOVAGRI. Disponivel em:<http://www.inovagri.org.br DOI: 10.7127/rbai.v11n400605> Acesso em: 15 jan. 2021.

HARA, A. T.; GONÇALVES, C.A.; DOMINGUES, J.V.S.; HASHIGUTI, H. T.; REZENDE, $R$ et al. Estabilidade temporal da variabilidade espacial da umidade do solo obtida no campo e no laboratório. Revista Brasileira de Agricultura Irrigada, v.12, n. 6, p. 3069-3077, 2019.

IDOETA, P.A. A agricultura é vilã ou vítima na crise hídrica?, BBC Brasil em São Paulo, 2015. Disponível em: $<$ https://www.bbc.com/portuguese/noticias/2015/03/150302_agua_agricultura_pai\# 
: :text=Safras\%20como\%20as\%20de\%20feij\%C3\%A3o,por\%20conta\%20da\%20 crise $\% 20 \mathrm{~h} \% \mathrm{C3} \%$ ADdrica.\&text=Ananias $\% 2 \mathrm{C} \% 20 \mathrm{da} \% 20 \mathrm{CNA} \% 2 \mathrm{C} \% 20$ explica\%2 Oque, humano\%2C\%20e\%20n\%C3\%A3o\%200\%20agr\%C3\%ADcola.>Acesso em: 21 jul. 2020.

KITIĆ, G.; BEGIN, V.C. A Sensor for the Measurement of the Moisture of Undisturbed Soil Samples. v. 13, n. 2, p. 1692-1705, 2013. Disponível em: <DOI: 10.3390 / s130201692. > Acesso em: 21 out. 2020.

LI, D.; SHAO, M. Temporal stability of soil water storage in three landscapes in the middle reaches of the Heihe River, northwestern China. Environmental Earth Sciences, v. 73, n. 7, p. 3095-3107, 2014. Disponível em:<DOI 10.1007/s12665014-3604-z> Acesso em: 10 fev. 2021.

MAROUELLI, W.A.; FREITAS, V.M.T.; COSTA JÚNIOR, A.D.; Guia prático para uso do Irrigas ${ }^{\circledR}$ na produção de hortaliças. Empresa Brasileira de Pesquisa Agropecuária. Embrapa Hortaliças Ministério da Agricultura, Pecuária e Abastecimento. Brasília: DF. 2010.

MEDEIROS, P.H.S. Sistema de irrigação automatizado para plantas caseiras. Trabalho de Conclusão de Curso -Engenharia de Computação, Universidade Federal de Ouro Preto, João Monlevade - MG, 2018. 54f. Disponível em: $<$ https://www.monografias.ufop.br/bitstream/35400000/1199/1/MONOGRAFIA_Sis temalrriga\%C3\%A7\%C3\%A3oAutomatizado.pdf> Acesso em: 01 fev. 2021.

MOREIRA, W.H.; TORMENA, C.A.; KARLEN, D.L.; SILVA, A.P.D.; KELLER, T. et al. Seasonal changes in soil physical properties under long-term no tillage. Soil and Tillage Research, v. 160, p. 53-64. 2016. Disponível em:< DOI: 10.1016/j.still.2016.02.007> Acesso em: 05 fev.2021.

NASCIMENTO, F.A.L. Sistemas e manejo de irrigação de baixo custo. Capacitação continuada-Agricultura irrigada e Recursos Hídricos. Universidade Federal do Recôncavo da Bahia, Cruz das Almas - Bahia- Ba, 2017. 17p. Disponível em: <https://www.ufrb.edu.br/neas/images/mat_did/CURSO-1--SISTEMAS-E-MANEJO-DE-IRRIGAO-DE-BAIXO-CUSTO.pdf.> Acesso em: 08 fev. 2021.

OLIVEIRA, A. R.; BRAGA, M. B.; SANTOS, B. L. S.; WALKER, A. M. Biometria de cultivares de cana-de-açúcar sob diferentes reposições hídricas no Vale do Submédio São Francisco. Revista Energia na Agricultura, v. 31, n. 1, p. 48-58, 2016. Disponivel em:< DOI:10.17224/EnergAgric.>2016v31n1p48-58.

OLIVEIRA, C.L. Calibração de sensores de umidade do solo de baixo custo. Trabalho de Conclusão de Curso- Agronomia - Universidade Federal Rural de Pernambuco, Garanhuns-PE, 2018. 50f. Disponível em: <https://repository.ufrpe.br/handle/123456789/1132.> Acesso em:08 fev. 2021.

PEREIRA, Y.M.; MIRANDA, R.F.; ALVES JÚNIOR, J.; CASAROLI, D.; EVANGELISTA, A.W.P. Calibração do sensor ECH2O, modelo EC-5 para Latossolo vermelho distrófico. Global Science Technology, v.11, n.03, p.68-76, set/dez. 2018. 
PIZETTA, S.C.; RODRIGUES, R.R.; PEREIRA, G.M.; PACHECO, F.E.D.; VIOLA, M.R.; LIMA, L.A. Calibração de um sensor capacitivo para estimativa da umidade em três classes de solos. Irriga, v. 22, n. 3, p. 458-468, 2017. Disponível em: https://doi.org/10.15809/irriga.2017v22n3p458-468 Acesso em: 08 fev. 2021.

RABOT, E., WIESMEIER, M., SCHLÜTER, S., VOGEL, H.J., 2018. Soil structure as an indicator of soil functions: A review. Geoderma v.314, p.122-137, 2018. Disponível em: <DOI: https://doi.org/10.1016/j.geoderma.2017.11.009>

SENAR- Serviço Nacional de Aprendizagem Rural. Irrigação: gestão e manejo. / Serviço Nacional de Aprendizagem Rural. Brasília: Senar, 2019.

SILVA, L. P.; SILVA, M. M.; CORREA, M. M.; SOUZA, F. C. D.; SILVA, E. F. F.Desempenho de gotejadores autocompensantes com diferentes efluentes de esgoto doméstico. Revista Brasileira de Engenharia Agrícola e Ambiental v.16, n.5,p.480-486, 2012. Campina Grande, PB. ISSN 1415-4366.Disponivel em: <http://dx.doi.org/10.1590/S1415-43662012000500003>Acesso em: 05 fev.2021.

SILVA, A.J.P.S.; COELHO, E.F.C.; FILHO, M.A.C.; SOUZA, J.L.S. Water extraction and implications on soil moisture sensor placement in the root zone of banana/ Extração de água e implicações na colocação do sensor de umidade do solo na zona da raiz da banana. Scientia Agricola (Piracicaba, Braz.), v. 75, n. 2 Piracicaba: SP. 2018. Disponível em: <DOI: http://dx.doi.org/10.1590/1678-992X2016-0339. $>$ Acesso em: 02 fev.2021.

SOULIS, K.X.; ELMALOGLOU, S. Optimum soil water content sensors placement in drip irrigation scheduling systems: concept of time stable representative positions. Journal Irrigation and Drainage Engineering, v. 142, n. 11, p. 04016054-1-04016054-9, 2016. Disponível em: <https://ascelibrary.org/doi/abs/10.1061/\%28ASCE\%29IR.1943-4774.0001093.> Acesso em: 12 fev.2021.

SOULIS, K. X.; ELMALOGLOU, S. Optimum soil water content sensors placement for surface drip irrigation scheduling in layered soils. Computers and Electronics in Agriculture, v. 152, p. 1-8, 2018.

SOUSA, V.F.; NUNES, G.M.V.C.; ZONTA, J.B.; ARAUJO, E.C.E.Tecnologias para a produção de melancia irrigada na Baixada Maranhense. São Luís: Embrapa Cocais, 2019.

TESTEZLAF, R. Irrigação: Métodos, Sistemas e Aplicações. Ed. Revisada. Não publicada. Campinas, SP: Faculdade de Engenharia Agrícola/UNICAMP 2017. 